\title{
EXCLUSÃO SOCIAL E COMPOSIÇÃO DE PERSONAGENS NA FICÇÃO DE JOÃO ANTÔNIO E DE LUANDINO VIEIRA
}

Vima Lia Martin

Universidade de São Paulo

A

exclusão social é uma das marcas mais terríveis dos países que, como os de língua oficial portuguesa, ocupam um espaço periférico no cenário mundial. E, no conjunto dessas nações, a situação do Brasil e principalmente a dos países africanos é ainda mais dramática, já que os elementos fundamentais de formação e evolução históricas de cada ex-colônia relacionam-se diretamente à exploração de seres humanos e de riquezas materiais típica do colonialismo.

A gradual e irreversível destruição causada pelo invasor português em terras brasileiras e africanas foi marcada não apenas pela violência militar, responsável por incontáveis mortes, mas também pela profunda desestruturação do modo de vida e dos valores culturais das populações nativas. Sobre a brutalidade dos primeiros embates entre o povo colonizador e os povos colonizados foram-se estabelecendo várias estratégias políticas para garantir a primazia econômica de Portugal - e de outros países mais desenvolvidos de que ele também dependia - sobre os territórios ocupados.

Essa realidade secular certamente que adquiriu contornos próprios em cada uma das ex-colônias, mas é um legado comum que se traduz, em parcela significativa da produção literária desses países, na construção de obras ficcionais representativas dos problemas cotidianos enfrentados pelas populações socialmente marginalizadas, parte deles decorrentes da sistemática da colonização.

As formas de consolidação das sociedades que compartilham de um mesmo passado de dependência em relação à ex-metrópole portuguesa, como 
Brasil e Angola, geraram a existência de uma extensa camada popular que foi obrigada a ocupar um lugar imposto. Trata-se das margens, onde as minorias, com pouca ou quase nenhuma cultura formal, escravizadas, subempregadas ou desempregadas, têm-se debatido contra um Estado que, reiteradamente, busca ocultá-las e silenciá-las.

Mesmo no caso de Angola, que conquistou sua autonomia política através da organização e da luta de parcelas importantes da população e instituiu, num primeiro momento, um governo socialista, a independência não foi capaz de estabelecer e dar continuidade a uma efetiva transformação social. O que se observa de fato é uma exclusão social cada vez mais acentuada, que foi agravada pela guerra civil que se desenvolveu posteriormente.

No contexto das literaturas brasileira e angolana destacam-se alguns ficcionistas que evidenciam o caráter centralizador e segregador dos projetos civilizadores impostos pelas elites governantes, elegendo especialmente figuras marginalizadas para protagonizarem seus textos. É o caso do brasileiro João Antônio (1937-1996) e do angolano Luandino Vieira (1935), que tecem narrativas sobre os desafios presentes no cotidiano das populações excluídas, desconstruindo o olhar autoritário e preconceituoso que geralmente as caracteriza. Em seus textos, que recriam a dicção característica desses segmentos sociais, a perspectiva não é mais a de quem exclui e violenta, mas a de quem é excluído e violentado.

\section{Mariazinha e Dina, entre a melancolia e a utopia}

Para ilustrar a composição de personagens desenvolvida por João Antônio e por Luandino Vieira, escolhemos, de uma grande galeria de personagens marginalizadas, duas mulheres que protagonizam e dão títulos a contos dos escritores. Trata-se de jovens prostitutas que vivem em profunda tensão com as duras realidades que enfrentam nas cidades do Rio de Janeiro e de Luanda: Mariazinha Tiro a Esmo, concebida pelo escritor brasileiro, e Dina, concebida pelo escritor angolano.

"Mariazinha Tiro a Esmo", publicado pela primeira vez em 1975, é um texto de difícil enquadramento em termos de gênero. Situa-se nas fronteiras entre a ficção, o depoimento e a reportagem, pois o narrador ora se comporta 
como um contador de histórias convencional, descrevendo com sensibilidade aspectos caracterizadores da jovem protagonista: "O sol bate e rebate nos cabelos da criança”; ora sai de cena, cedendo totalmente a voz para Mariazinha contar a sua própria história: “- Meu neguinho, foi mais ou menos assim.”; ora atua como um repórter, que vai às ruas em busca de personagens de carne e osso e as descreve com extrema crueza: "Aos nove anos fez o primeiro crime: meteu gilete no escorregador de uns meninos que a surravam”. Vale observar que essa oscilação do foco narrativo instaura uma visão prismática capaz de expressar o estilhaçamento do universo marginal retratado pela narrativa: diferentes perspectivas se complementam para ampliar a perplexidade suscitada pela própria natureza da experiência narrada.

Como um mosaico, sem obediência a uma cronologia linear, alguns episódios vão compondo a história de Mariazinha. História que é sua e é também de muitas outras "meninas de rua" como ela. Catorze anos, filha de uma prostituta e de um ferroviário alcoólatra, desde muito nova aprendeu a sobreviver no meio da violência e da malandragem reinantes na favela da Catacumba. Olheira da indústria de pedintes, é responsável por seis meninas que esmolam e vendem bugigangas em Copacabana. Mas apesar da vida cheia de dificuldades e de riscos, Mariazinha "não se dá por ofendida". Não gosta de causar pena e assume-se como piranha, demonstrando um certo conformismo diante de um destino mais do que esperado para quem nunca encontrou oportunidades para viver de outra maneira: “- Sou piranha, e daí? Eu tenho culpa? Acho que não gostaria de ser. Seria bom ter um homem só com um carro só. Parece que seria legal. Mas está aí uma coisa que os homens não querem”.

Essa fala final, que encerra a narrativa, ao mesmo tempo que revela o sonho de Mariazinha, a sua aspiração por deixar de ser prostituta e viver a exclusividade de um único relacionamento, traz também um desabafo (Eu tenho culpa?), que desloca a responsabilidade dessa situação para uma esfera mais ampla do que a de sua trajetória individual. Também na última frase, a expressão da consciência da jovem de que tal sonho é impossível volta-se novamente para a realidade exterior a ela, fora do alcance de seu desejo e de seu campo de atuação: "Mas está aí uma coisa que os homens não querem". A impossibilidade de ação parece ser um imperativo na vida da protagonista.

Diferentemente do que se dá na história de Mariazinha, na estória de “Dina”, escrita em 1962, o destino da moça parece estar em suas próprias 
mãos. Também o fio da narrativa parece estar nas mãos de um narrador onisciente que assemelha-se ao narrador tradicional, conservando, para valermo-nos das palavras de Walter Benjamin, a "faculdade de intercambiar experiências e a sabedoria de aconselhar: o conselho tecido na substância viva da existência tem um nome: sabedoria” (BENJAMIN, 1993, p..200).

Logo na primeira linha, o conto é inaugurado com dados que atestam a sua referencialidade: "Estes casos passaram no Santo Rosa, em Maio de 61". A demarcação do espaço de resistência do musseque luandense e dos momentos iniciais da Guerra de Libertação remetem o leitor para um campo ficcional que se afirma como realidade e que dialoga de perto com os fatos históricos decisivos para a independência de Angola.

A personagem central do conto, uma jovem que tem a sua vida marcada pela dominação e pelo autoritarismo do governo português, é flagrada, ao entardecer, sentada à porta da cubata onde mora. Uma grande tristeza começa a invadi-la, pois, à noite, cumprindo a vontade de sua madrinha, deverá se deitar com um soldado, e só a lembrança do cheiro do suor de sua farda causa-lhe nojo por antecipação. Rememora, então, os assassinatos do pai e da mãe, cometidos pela polícia em 1943 ou 1944, quando ela tinha apenas cinco anos. Desde então, tem sido criada pela velha Mabunda, que vê a prostituição como decorrência natural da situação da afilhada, não entendendo sua raiva diante de tal condição.

Repentinamente os pensamentos de Dina são interrompidos pela cena de um velho sendo perseguido, espancado e morto por policiais bem à sua frente. Assistir a tal absurdo faz com que a moça se revolte e resolva enfrentar os soldados, sendo surrada também. Depois, ao ser levada de carro pela polícia, Dina sente-se feliz. O assassinato do velho, provavelmente considerado como terrorista pela PIDE, remetera a moça às inesquecíveis mortes do pai e da mãe e lhe dera forças suficientes para decidir de uma vez por todas que não mais manteria relações sexuais com nenhum soldado do exército português. A decisão e a alegria da jovem - expressas com um berro e interpretadas como desvario pelo policial que a acompanhava - marcam uma nova existência "a disparar dentro dela".

A situação vivida pelas protagonistas Mariazinha Tiro a Esmo e Dina em muito se assemelham. De origem pobre e criadas sem a presença dos pais, ambas encontram na prostituição uma maneira de sobreviver num uni- 
verso miserável e violento. A falta de condições de uma vida digna deixa sintomaticamente suas marcas na precariedade do próprio corpo das moças: Mariazinha tem os dentes podres e Dina, uma ferida aberta no pé. Mas, embora vivendo situações similares de marginalidade social, a maneira como cada uma delas se relaciona com a sua própria vida é essencialmente diferente. Como um tiro dado a esmo, ao acaso, à toa, também a trajetória de Mariazinha parece não ter rumo. E os seus sentimentos de conformismo e melancolia - esta, sobrepujada pela dureza e pela indiferença tão necessárias à sobrevivência nas ruas - opõem-se à tristeza e à raiva sentidas por Dina.

E é essa raiva - "Não era ainda raiva na velha, não, era raiva na vida, raiva de tudo" - que faz a moça angolana resistir à opressão, enfrentando a polícia e decidindo abandonar a prostituição. Depois desses atos de coragem, a raiva de Dina se transforma na alegria de se saber participante de uma história de libertação.

Nessas narrativas escritas por João Antônio e por Luandino Vieira, as protagonistas são portadoras de um código ético que permite que elas se posicionem com mais ou menos independência e autodeterminação diante das desumanas realidades com que se confrontam.

Na narrativa de João Antônio, o senso moral e a consciência ética de Mariazinha se definem a partir de imperativos imediatos, relacionados com a sua sobrevivência. $\mathrm{O}$ ethos da personagem, relativo às virtudes e vícios que ela é capaz de praticar (CHAUÍ, 1995, p.340), parece se conformar às miseráveis condições de vida enfrentadas por tantos homens, mulheres e crianças como ela: "Dura, vivida, batida, já usada. Falando é crua, descarnada. Mas inflexível com as leis e a ética da malandragem”. A necessidade da viração, do como arranjar-se para suportar mais um dia em meio à violência urbana, faz com que a conduta da jovem seja condicionada pelas leis e a ética da malandragem. E, nesse universo sem saída, não cabe a deliberação ou a decisão a respeito do presente e, conseqüentemente, do futuro. No “corpo-a-corpo" com a vida, Mariazinha não vislumbra nenhuma possibilidade de transformação em seu horizonte.

Já no caso de Dina, há uma ética, ou um saber prático, que claramente orienta a sua ação, e essa práxis é de alguma forma ensinada pelo próprio desenvolvimento da narrativa. Como o "sujeito ético", definido pela filosofia grega, a jovem "não se submete aos acasos da sorte, à vontade e aos desejos 
de um outro, à tirania das paixões, mas obedece apenas à sua consciência que conhece o bem e as virtudes - e à sua vontade racional - que conhece os meios adequados para chegar aos fins morais" (idem, p.342).

Desse modo, a segurança e a felicidade alcançadas pela moça depois de sua intervenção junto à polícia que perseguia o velho no musseque e de sua resolução de não mais se prostituir são índices que atestam o acerto dessas suas atitudes, mesmo que tomadas no calor da hora. É como se um percurso - do sentimento à razão/ação - tivesse se cumprido: a tristeza e raiva sentidas por tanto tempo gestam o ato verdadeiramente transformador. $\mathrm{O}$ desfecho da narrativa proclama a consciência de que o agente, a ação e a finalidade do agir são elementos inseparáveis no processo de aquisição e desempenho de uma práxis revolucionária, essencialmente utópica.

Numa leitura comparativa entre "Mariazinha Tiro a Esmo" e "Dina", é possivel contrapor uma perspectiva melancólica e uma perspectiva utópica características de cada uma das narrativas. Além do próprio andamento do enredo, o foco narrativo, vale assinalar, assume papel importante na construção desses sentidos. A fragmentação discursiva do texto de João Antônio contrasta com a onisciência centralizadora do discurso criado por Luandino, colaborando para a instituição de perspectivas que se opõem.

$\mathrm{Na}$ primeira narrativa, Mariazinha é co-participante no processo de enunciação e é, ela mesma, porta-voz das contradições com que se debate, o que só acentua a inexistência de respostas plausíveis para as questões vividas por ela. Esse processo de "desidealização da realidade", que comporta uma certa radicalidade estética e ideológica, promove, segundo Flávio Aguiar, uma espécie de "deseducação do leitor". Trata-se de mostrar "as coisas como elas são", deseducando o leitor para a apreciação de um literatura que seja o adorno, ou o sorriso da sociedade, ou mesmo, e isso também é decisivo, uma literatura que se torne autocomplacente consigo mesma pela louvação da denúncia” (AGUIAR, 1999, p.118). A denúncia ou a constatação dos aspectos mais desumanos da realidade impedem o leitor de conformar-se diante do que é socialmente indesejável e pode dar início à formação de uma nova consciência.

Em "Dina", há um direcionamento ideológico mais claro na condução do drama vivido pela protagonista. Em vez de mostrar "as coisas como elas são", o texto mostra "as coisas como elas deveriam ser". Mas longe de sublinhar 
uma visão ingênua da sociedade ou uma posição autocomplacente, essa postura aposta numa transformação social efetiva. As palavras finais do conto proferidas pelo narrador, que arrematam a história afirmando um ponto de vista positivo sobre o suposto desvario da moça, funcionam como uma espécie de conselho para todos aqueles que desejam ser sujeitos da própria história.

Como numa narrativa tradicional, há uma dimensão utilitária no fato narrado e essa utilidade traduz-se em um ensinamento moral, funcionando como exemplo a tantos angolanos marginalizados e oprimidos como a personagem. Nesse sentido, o discurso oferece quase uma resposta às questões problematizadas, promovendo o que poderíamos compreender como um processo de "educação do leitor".

O texto de João Antônio é melancólico porque desmitifica a realidade, expressando um sentimento de impotência diante dela. Ao constatar os reais descaminhos percorridos pelos muitos marginalizados da sociedade brasileira, a narrativa denuncia, com lucidez e desencanto, o autoritarismo e a exclusão enraizados no país.

Já o texto de Luandino Vieira é utópico, porque, de certa maneira, mitifica, idealiza: ao contestar a ordem que estrutura a sociedade, a narrativa não apenas expõe a exclusão social, mas também indica um caminho revolucionário para superá-la. Vale frisar que a utopia presente na obra de Luandino, embora propositiva, "concreta", vincula-se a um imaginário, estabelecido a partir de um modelo de organização justo, harmonizado e sem classes. E é essa imagem idealizada de sociedade, sugerida em várias de suas narrativas, que está absolutamente ausente do horizonte do conjunto das narrativas de João Antônio.

Melancolia e utopia são, assim, causa e conseqüência de discursos literários tecidos como resistência, que constatam e contestam os absurdos decorrentes da ordem institucionalizada nas Histórias recentes do Brasil e de Angola.

\section{BIBLIOGRAFIA}

AGUIAR, Flávio. "Evocação de João Antônio ou do purgatório ao inferno". Revista Remate de Males, no 19, UNICAMP, 1999. 
ANTÔNIO, João. Malhação do judas carioca. Rio de Janeiro: Civilização Brasileira, 1976.

BENJAMIN, Walter. "O narrador. Considerações sobre a obra de Nikolai Leskov". In:

Obras escolhidas (vol I). São Paulo: Brasiliense, 1993.

CHAUÍ, Marilena. Convite à filosofia. São Paulo: Ática, 1995.

VIEIRA, José Luandino. Vidas novas. Lisboa: Edições 70, 1997. 